\title{
Prevalence of wound, its associated risk factors and wound management practices in carthorses of ten selected towns of Ethiopia
}

\author{
Mihret Teferi, Reta Tesfaye*, Hanna Zewdu, Gizaw Gemechu, Gebre Tefera, Tibebu \\ Ashine \\ Addis Ababa University, College of Veterinary Medicine and Agriculture, the Society for Protec- \\ tion of Animals Abroad (SPANA) Ethiopia project \\ *corresponding author: Reta Tesfaye, email: reta.tesfaye@gmail.com
}

\begin{abstract}
A cross-sectional study was conducted from November 2017 to April 2018 to estimate the prevalence of wound and associated risk factors in carthorses, and to assess wound management practices in 10 selected towns of Ethiopia. The study was conducted through personal interview and observation of carthorses. Randomly selected 390 drivers and their carthorses were included in this study. The study revealed that, the overall prevalence of wound was $51.5 \%(\mathrm{n}=201)$. The prevalence of wound significantly varied among the study towns. It was high $(70 \%, \mathrm{n}=28)$ in Shashemene and low $(30 \%, \mathrm{n}=9)$ in Sheno. More than one type of wound was the most common $(21 \%, \mathrm{n}=82)$ type to occur. Harness related wounds such as girth sore $(20.8 \%, \mathrm{n}=81)$, chest sore $(11.8 \%$, $\mathrm{n}=46)$, bit sore $(11.8, \mathrm{n}=46)$, saddle sore $(7.9 \%, 31)$, tail sore $(3.1 \%, \mathrm{n}=12)$ and collar sore $(0.5 \%, \mathrm{n}=2)$ were observed. The non-harness related wounds identified were fetlock sore $(12.3 \%, \mathrm{n}=48)$, knee sore $(3.3 \%, \mathrm{n}=13)$, whip sore $(3.1 \%$, $\mathrm{n}=12)$ and other sores $(1.5 \%, \mathrm{n}=6)$. Generally, wound related with harnesses were more frequent. The prevalence of wound was observed significantly different between body condition scores. Horses with body condition score 2 were 2 times more likely to be wounded than horses with better body condition score $(\mathrm{BCS}=3)$ [OR: 2.4 95\%CI (1.36-4.25)]. Wound prevalence was low in horses where owner own only one horse compared to owners keeping two and more horses [OR: 1.56, 95\% CI (1.01-2.33)]. Bits with smooth surface were used in less than half $(44.4 \%, \mathrm{n}=173)$ of the observed animals. Variation in frequency of bit sore was observed based on bit types used. The majority of bit sores were caused by metal bits with rough surface $\left(\mathrm{x}^{2}=10.52, p=0.03\right)$. Majority $(83.3 \%, \mathrm{n}=325)$ of the owners were aware of proper wound management practices. Carthorses often transport 3 to 4 people at a time, the average working
\end{abstract}


hours being 6.22 hours per day. In conclusion, the study has indicated wound as highly prevalent health and welfare problem of carthorses in the study area. Therefore, intervention should be in place to reduce the prevalence of wound. Cart horses should be fed well to keep them in a good body condition. Proper type of bits, harnessing materials and cart design should be used. Non-harness related wound should also be avoided.

Key words: Carthorse; Ethiopia; Prevalence; Risk factors; Wound

\section{Introduction}

Equine are important working animals for the resource-poor communities of rural and urban areas of Ethiopia (Wilson, 1991; Starkey and Fielding, 2000; Mengistu, 2003). They are used for various purposes. In rural areas, equines are used to transport people and items from one place to another. They carry water for home consumption and transport goods to and from market. They are also involved in agricultural activities such as transport of agricultural products from field to home. Their contribution in social events such as holidays, wedding and funeral ceremonies is also significant (SPANA, 2019, unpublished). In urban and peri-urban areas, horses are mainly used in pulling carts to transport people and materials such as water, crop, vegetable, construction materials, firewood and other goods to market (Mekuriaw, 2019). Equine owners rely on the direct or indirect income generated from these animals and life would be very difficult without them (Mekuriaw, 2019; SPANA, 2019, unpublished).

Wound is one of the most common equine health problems in daily veterinary practice. Wound beneath overlying tack or equipment is the most frequent type of wound to occur in equine (Pritchard et al., 2005). Wound compromise the welfare of equine, reduces work efficiency and predispose the animal to diseases. Wound can involve superficial layer, deep skin underlying tissue or it may involve vital structures such as joints (Knottenbelt, 2003; Stashak and Theoret, 2008).

There are few studies conducted on equine wound in the study area. Understanding the status of wound and owners' practice with regards to wound management is crucial for prevention and control of wound in equine. Therefore, the present study aims to estimate the prevalence of wound and identify its 
associated risk factors, and assess owners' wound management practice in carthorses.

\section{Materials and methods}

\section{Study area}

The study was conducted in 10 towns, namely, Adama, Akaki, Bishoftu, DebreBrihan, Hawassa, Holeta, Modjo, Sebeta, Shashemene and Sheno. They are located within about 275 kilometers radius from Addis Ababa, capital of Ethiopia. These sites have different agro ecology ranging from midland with an altitude range of 2200-2600 meters above sea level to highland with an altitude of above 2600 meters. Debre-Brihan and Sheno belong to highland category while the remaining towns are in an altitude range of midland. Horses in these towns were used for pulling carts to transport people, agricultural products and inputs, and construction materials among others. They provide service within the towns and to the nearby peri-urban areas.

\section{Study design}

A cross sectional study was conducted from November 2017 to Aril 2018 in 10 selected towns. Personal interview was conducted on randomly selected 390 carthorse drivers and physical examination was conducted on carthorses of the same drivers. The questionnaire included information on socio-demography of carthorse drivers such as sex, age, level of education, marital status, carthorses' driving experience, horse ownership and duration of relationship with the horse. Besides, number of people transported per trip, working hours per day, time taken per trip and resting time between trips were recorded by asking the owners.

Practices of carthorse drivers on wound management were also assessed during the interview. The practices were categorized as modern, traditional and unacceptable treatments. Modern treatment refers to treating animal with scientifically accepted wound management practices. Traditional treatment included the use of medicine such as herbs known for wound treatment by the community or traditional healers. Unacceptable treatment practices refer to application of agents that are known to hinder wound healing such as battery acids, mud, engine oil and caustic chemicals. The use of the unacceptable 
wound treatment in combination with any other one was considered as unacceptable treatment approach.

During physical examination of the selected horses, age, body condition score, location of the wound and types of bits used were recorded. Age of the horses was determined based on dental eruption pattern. Horses were grouped as young and adult. Those horses who fully replaced all incisor milk teeth were grouped as adult and others were categorized as young. Scoring of the body condition was based on 1 to 5 scales (AWIN, 2015). External injuries were considered in this study. Scars, alopecia, specific disease conditions such as epizootic lymphangitis and sarcoid were not included as wound.

\section{Sampling technique and sample size}

To determine the sample size, the expected prevalence in the study area was assumed $42 \%$ at confidence interval of $95 \%$ (Chala et al., 2017). The formula given by Thrusfield (2007) for simple random sampling method was used.

$\mathrm{N}=1.96^{2} *$ pexp * $(1-\mathrm{pexp}) / \mathrm{d}^{2}$

Where: $\mathrm{N}=$ required sample size, Pexp=expected prevalence, $\mathrm{d}=$ desired absolute precision. Accordingly, the calculated sample size was 374 and 390 horses were sampled.

Ten towns were selected from central part of Ethiopia. Almost equal number of carthorses was selected from each town. Accordingly, forty horses were selected from the nine towns and in one town 30 horses were selected. Systematic random sampling was used in selecting individual horses from their stations where they line to wait for their turn to transport people and goods.

\section{Data analysis}

Data collected from the study sites were coded and entered to Microsoft excel spreadsheet program for analysis. Statistical analysis was done by Statistical Package for Social Sciences (SPSS) software version 20. Descriptive statistics, percentage, was used to express prevalence and socio-demography of the participants. Chi-square $\left(x^{2}\right)$ test was used to check which variables have 
association with the dependent variable individually. Variables found to have a $\mathrm{P}$-value of $<0.2$ in $\mathrm{X}^{2}$ test was entered into multivariable logistic regression model for controlling the possible effect of confounders and finally variables which had significant association were identified based on $95 \%$ confidence interval. Odds Ratio (OR) was used in assessing the strength of association.

\section{Results}

\section{Demography of the respondents}

Almost all carthorse drivers interviewed were male. The proportion of young age group was very high compared to other age groups. Different level of education was recorded with most people being grade 1-8. More than half of the drivers had been involved as a carthorse driver for less than two years. The majority of the respondents drive their own horse while small proportion were recruited as a driver or rent horses from others. Most of the respondents own two horses followed by those who own one horse. Limited number owns three or more horses. Nearly $90 \%$ of the horses had been working for up to only 2 years. The demographic characteristics of the respondents are summarized in table 1 . The mean family size of the respondents was 4.3 , ranging from the carthorse driver himself alone to 14 families supported by the income generated from carting. 
Table 1: Demographic characteristics of the respondents $(n=390)$

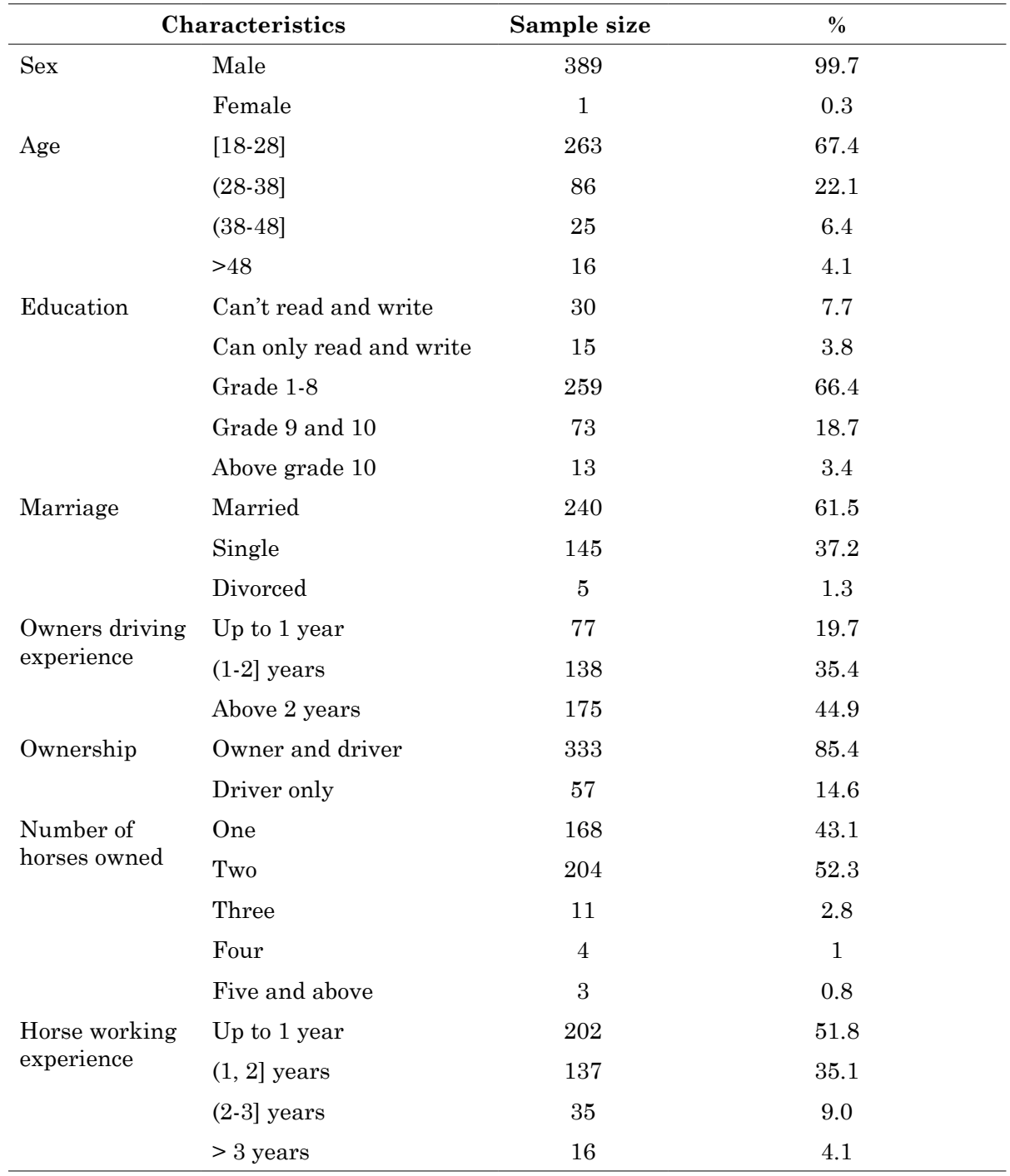

\section{Prevalence and types of wound}

The overall prevalence of wound in the carthorses was 51.5\% (201/390). The prevalence was significantly different among the study sites (Table 2). 
Table 2: Prevalence of wound in carthorses in selected towns of central Ethiopia $(n=390)$

\begin{tabular}{|c|c|c|c|c|}
\hline Study towns & $\begin{array}{l}\text { Number of } \\
\text { horses with } \\
\text { wound }\end{array}$ & $\begin{array}{l}\text { Prevalence } \\
(\%)\end{array}$ & $x^{2}$ & $p$-value \\
\hline Sheno & 9 & 30.0 & \multirow{10}{*}{21.23} & \multirow{10}{*}{0.01} \\
\hline Debre-Brihan & 13 & 32.5 & & \\
\hline Akaki & 18 & 45.0 & & \\
\hline Bishoftu & 19 & 47.7 & & \\
\hline Modjo & 21 & 52.5 & & \\
\hline Sebeta & 22 & 55.0 & & \\
\hline Holeta & 22 & 55.0 & & \\
\hline Hawassa & 24 & 60.0 & & \\
\hline Adama & 25 & 62.5 & & \\
\hline Shashamene & 28 & 70.0 & & \\
\hline
\end{tabular}

Wound was observed on various body parts of the animals due to various causes. Wound on more than one body parts accounted $21 \%$. Girth sore was also almost equal to this; $20.8 \%$. Generally, several harness related wounds with high proportion were found in the study area. Fetlock sore is most common from the non-harness related wounds and others occur less frequently (Table 3).

Table 3: Types of wound based on its location on animals' body or its causes $(\mathrm{n}=390)$

\begin{tabular}{lcc}
\hline Types of wound & Number of animals with wound & Prevalence (\%) \\
\hline More than one type of wound & 82 & 21 \\
Girth sore & 81 & 20.8 \\
Fetlock sore & 48 & 12.3 \\
Chest sore & 46 & 11.8 \\
Bit sore & 46 & 11.8 \\
Saddle sore & 31 & 7.9 \\
Knee sore & 13 & 3.3 \\
Whip sore & 12 & 3.1 \\
Tail sore & 12 & 3.1 \\
other wounds & 6 & 1.5 \\
Collar sore & 2 & 0.5 \\
\hline
\end{tabular}




\section{Types of bit and associated wound}

From 390 horses examined 173 (44.4\%) were using imported bit made of metal which do not rust and has smooth surface. The remaining were using bits locally made of metal having different size and surface texture. The difference in prevalence of bit sore in relation to bit types used was significant. Majority of bit sores were caused by bits made of metal with rough surface (Table 4).

Table 4: Wound associated with different types of bits $(n=46)$

\begin{tabular}{llll}
\hline Type of bit & $\begin{array}{l}\text { Frequency } \\
(\mathrm{n})\end{array}$ & $\begin{array}{l}\text { Proportion } \\
(\%)\end{array}$ & P value \\
\hline Metal bit with smooth surface & 11 & 6.4 & 0.003 \\
Metal bit with different size and texture & 35 & 16.1 & \\
\hline $\mathrm{x}^{2}=10.52$ & &
\end{tabular}

\section{Factors associated with wound occurrence}

Chi-square test indicated that, educational status, number of horses owned and body condition score of the horses were a possible risk factors associated with the occurrence of wound $(p<0.5)$. Other factors including age of the drivers, owners' driving experience, marriage status, ownership of the carthorse, horses' work experience, working hours per day and age of the horses were not statistically associated with the occurrence of wound. After the multivariable logistic regression analysis was applied, it was identified that animals' body condition score and number of horses owned had significant associations with the occurrence of the wound. Those horses who had body condition score 2 has shown about 2 times more likely to be wounded than horses scoring 3 [OR: $2.37,95 \%$ CI (1.34-4.20)]. Wound was 1.5 times higher in horses where owners owned two or more horses compared to horses where owners owned only one (Table 5). 
Table 5: Factors associated with wound occurrence

\begin{tabular}{lcccc}
\hline Variables & & $\begin{array}{c}\text { Wound } \\
\text { Yes }\end{array}$ & No & OR (95\%) CI \\
\hline Body condition score & 2 & 179 & 143 & $2.4(1.36-4.25)$ \\
Number of horses owned & 3 & 22 & 46 & \\
Age of the driver & More than 1 & 126 & 96 & $1.56(1.01-2.33)$ \\
& $18-28$ & 149 & 114 & $0.76(0.23-2.54)$ \\
& $29-39$ & 38 & 48 & $1.09(0.32-3.73)$ \\
Educational status & $40-49$ & 9 & 16 & $1.29(0.32-5.27)$ \\
& $>50$ & 6 & 10 & 1.00 \\
& Cannot read and & 15 & 15 & $2.79(0.69-11.38)$ \\
write & & & \\
& Can only read and & 4 & 11 & $1.05(0.47-2.36)$ \\
& write & & & \\
& Grade 1-8 & 134 & 125 & $0.81(0.32-2.03)$ \\
& Grade 9 and 10 & 45 & 28 & $3.48(0.76-15.89)$ \\
& Above 10 & 3 & 10 & 1.00 \\
\hline
\end{tabular}

\section{Number of people transported per trip}

Carthorses in the study area transport 3 to 10 people at a time. Most of them transport 3 to 4 people (Table 6 ).

Table 6: Number of people transported per trip

\begin{tabular}{ccc}
\hline Number of people transported & Frequency $(\mathbf{n})$ & $\mathbf{\%}$ \\
\hline $3-4$ & 335 & 89.8 \\
$5-6$ & 35 & 9.4 \\
$7-10$ & 3 & 0.8 \\
\hline
\end{tabular}

\section{Working hours}

Average working time per day stated was 6.22 hours, with maximum of 12 hours and minimum of 2 hours. Most of the horses work for 2-6 hours per day (Table 7). 
Table 7: working hours per day

\begin{tabular}{ccc}
\hline Working hours per day & Frequency $(\mathbf{n})$ & Percent \\
\hline $1-6$ & 273 & 70.4 \\
$>7-12$ & 115 & 29.6 \\
\hline
\end{tabular}

\section{Break time between trips}

The traveling time taken per trip and break time in between trips are summarized in table 8 .

Table 8: Traveling and break time

\begin{tabular}{lccc}
\hline Time & Mean (minutes) & Minimum (minutes) & Maximum (hours) \\
\hline Traveling time & 25 & 5 & 3 \\
Break time & 42 & 1 & 4 \\
\hline
\end{tabular}

\section{Wound management practice}

Majority (83.3\%) of the owners know how to properly treat or what to do when their horses are wounded. They treat with the acceptable treatment approach like washing with homemade saline water and or look for veterinary care. The remaining owners/ drivers used or believe to use traditional treatment as well as other unacceptable treatment options (Table 9).

Table 9: Wound management practice by carthorse owners/drivers

\begin{tabular}{lcc}
\hline Wound management & Frequency (n) & \% \\
\hline Modern treatment & 325 & 83.3 \\
Traditional treatment & 25 & 6.4 \\
Unacceptable treatment alone or in combination & 38 & 9.7 \\
to others & & 0.3 \\
Modern and tradition treatment & 1 & \\
\hline
\end{tabular}

\section{Discussion}

The current study revealed an overall wound prevalence of about $51 \%$ in carthorses. There was significant difference in the prevalence of wound among the study towns ranging from $30 \%$ to $70 \%$. The overall prevalence was lower than several reports from Ethiopia, which include $65.4 \%$ in Hawassa (Biffa and Woldemeskel, 2006), 64.2\% in Kombolcha (Fikru et al., 2015), 65.8\% in Asella 
(Abdela et al., 2017) and 68.2\% in Jimma (Genetu et al., 2017). However, it is higher than the finding of Chala et al. (2017) who reported 42.5\% in Bishoftu. This variation might be due to the difference in owners'/drivers' awareness on wound control and prevention, agro-ecology, cart design or type of harnessing materials used among the study areas.

The current study indicated the occurrence of wound on various parts of the body of carthorses. In majority (21\%) of the cases, the wounds were found in more than one body parts. Wounds related with harness were higher compared to human inflicted and accidental wounds. From harness related wounds the highest number of wounds was found on girth area, which accounted about $21 \%$ of the examined horses. Other harness related wounds such as bit sore, chest and saddle sores were also among frequently occurring wounds. Tail sore and sore due to collar were observed on few animals. In line with this, reports from Kombolcha and Asella towns indicated the occurrence of high proportion of harness related wounds (Fikru et al., 2015; Abdela et al., 2017). Harnesses have a close relationship to the body of the animal. The skin of equine is sensitive to rubbing, and rough materials or lack of enough padding can cause injury (Starkey, 1998). A properly designed, well-fitted and comfortable harness allows the working animal to pull the equipment to the best of its ability without risk of injuries (Pearson et al., 2006).

Among the non-harness related wounds, fetlock sore relatively accounted the largest proportion occurring in about $12 \%$ of the examined horses. Knee and whip sores were observed in about $3 \%$ of the horses and other non-harness related injuries was observed in $1.5 \%$ of the horses. Wound on fetlock might be due to problem in hoof conformation, improper shoeing practice and overworking of the horses, which might lead to fatigue, and kicking of foot together. Knee sore may be due to high speed during driving and overworking which could cause the animals to fall down. Whip sore is human made which might be done deliberately to force an animal to work or the horses might be beaten when they resist the order given by the drivers.

Higher proportion of bit sore was observed due to bits which were made of metal with rough surface. This result is in agreement with Mekuriaw (2019). These types of bits are not standardized to fit to the horses as this are locally 
produced by people with low knowledge about its fitness and comfort. This implies use of proper bit reduces the occurrence of bit sore significantly, and hence reduces animal suffering.

In this study, body condition score and number of horses owned were identified as risk factors. Wound was more common in horses having a body condition score of 2 compared to horses having better body condition $(\mathrm{BCS}=3)$. This finding is similar with report by several authors: Biffa and Woldemeskel (2006), Herago et al. (2015), Abdela et al. (2017), Chala et al. (2017) and Fsahaye et al. (2018). Horses with good body condition are strong enough to pull loads to the best of their ability without risk of injury. Horses with poor condition are incapable of pulling equipment/humans due to less transferred power from them to attached implement, this leads to fatigue as well as injury (Starkey, 1998). Besides, equids with low body condition score have reduced body fat and consequently, may have less natural padding protecting them from wound caused by harness (Pritchard et al., 2005).

Majority (83\%) of the owners treated their horses or believed that the wound should be treated with acceptable type of treatment like washing with homemade saline water and seeking for veterinary care. Others used traditional as well as other unacceptable treatment options. This result is in contrary with the result obtained in Kombolcha where majority (79.4\%) of the owners did not provide any treatment to their animal for wound. This might be due to variation in awareness among the carthorse owners/drivers about wound treatment.

Horses pulling carts transport commonly 3 to 4 people at a time. They work in average for about 6 hours a day. This is in line with report by Bifa and Woldemeskel (2006) who reported that pulling carts often work continuously for 6 to 7 hours/day, carrying 3 to 4 persons in a single trip.

\section{Conclusion}

Wound was highly prevalent health and welfare problem in the study area. Variation in the occurrence of wound was observed among the study sites. Harness related wound was more common to occur compared to the non-harness 
related wound. From the several potential risk factors assessed only body condition score and number of horses owned were found to have significant associations with the occurrence of wound. Some carthorse owners' apply agents that are known to hinder wound healing. Therefore, intervention should be implemented to reduce wound in the carthorses. Carthorses should be fed well to keep them in a good body condition. The harness and cart in use should fit the animal properly. Community education should be enhanced focusing on the negative impacts of wound, proper harnessing and wound management practices. Research should be conducted to identify the contribution of local cart design, harness materials in use and its fitness for wound occurrence in carthorses.

\section{Acknowledgements}

The authors acknowledge the Society for Protection of Animals Abroad (SPANA) Ethiopia Project for its financial support in this study. We also acknowledge the cooperation and support provided by the carthorse drivers during the interview and examination of the animals.

\section{Limitation of the study}

Harness materials used, cart design and fitness of the harnesses were not included in the current study.

\section{References}

Abdela, N., Teshome, E., Hassan, A. and Begna, F., 2017. Prevalence and associated risk factors of equine wound in and around Asella town, South Eastern Ethiopia. J. Vet. Med. Anim. Hlth., 9 (4), 63-71.

AWIN, 2015. AWIN welfare assessment protocol for horses. www.animal-welfare-indicators.net animalwelfarehub.com.

Biffa, D. and Woldemeskel, M., 2006. Causes and factors associated with occurrence of external injuries in working equines in Ethiopia. Int. J. Appl. Res. Vet. Med., 4 (1), 1-7.

Chala, F., Ayele, B. and Tariku, T., 2017. Prevalence of work-related wounds and the associated risk factors in cart horses in Bishoftu town, central Ethiopia. J. Biol. Agri. healthcare, 7(17), 80-86. 
Fikru, A., Tadese, A. and Gebreegziabher, Z., 2015. Prevalence of equine wound and associated risk factors in and around Kombolcha town, North Ethiopia. J. Vet. Sci. Technol., 6, 234.

Fsahaye, S., Kumar, N., Kebede, E. and Abebe, N., 2018. Health and welfare assessment of working donkeys in and around Rama town, Tigray, Ethiopia. Ethiop. Vet. J., 22 (1): 26-39.

Genetu, H., Yohannes, G., Abdela, N. and Ibrahi, N., 2017. Prevalence of wounds and associated risk factors in working equines in Jimma town of Oromia region, SouthWestern Ethiopia. Acad. J. Anim. Dis., 6 (2), 23-29.

Herago, T., Megersa, M., Niguse, A. and Fayera, T., 2015. Assessment on working donkey welfare issue in Wolaita Soddo Zuria District, Southern Ethiopia. Global Vet., 14 (6): 867-875.

Knottenbelt, D. C., 2003. Hand book of equine wound management, Elsevier Science Limited, UK.

Mekuriaw, H., 2019. The socio-economic importance of horses used for carting in Bishoftu, central Ethiopia. DVM Thesis, College of Veterinary Medicine and Agriculture, Addis Ababa University, Bishoftu, Ethiopia.

Mengistu, A., 2003. The genetic resources perspective of equines in Ethiopia and their contribution to the rural livelihoods. In: Proceedings, The $11^{\text {th }}$ Annual Conference of the Ethiopian Society of Animal Production (ESAP), Addis Ababa, Ethiopia.

Pearson, R. A., Simalenga, T. E. and Krecek, R. C., 2006. Harnessing and hitching donkeys, horses and mules for work. Centre for Tropical Veterinary Medicine, University of Edinburgh, Scotland, UK.

Pritchard, J. C., Lindberg, A. C., Main, D. C. J. and Whay, H. R., 2005. Assessment of the welfare of working horses, mules and donkeys, using health and behavior parameters. Prev. Vet. Med., 69(3-4), 265-283.

Starkey P., 1998. Harnessing and implements for animal traction. An animal traction resource book for Africa. Lengericher Handelsdruckerei, Germany.

Starkey, P. and Fielding, D., 2000. Donkeys, people and development. A resource book of the Animal Traction Network for Eastern and Southern Africa (ATNESA). ACPEU Technical Centre for Agricultural and Rural Cooperation (CTA), Wageningen, The Netherlands.

Stashak, T. S. and Theoret, C., 2008. Equine Wound Management $2^{\text {nd }}$ edition, WileyBlackwell, USA.

Thrusfield, M., 2007. Veterinary Epidemiology, $3^{\text {rd }}$ edition, Blackwell science. UK. 
Wilson, R. T., 1991. Equines in Ethiopia. In Proceedings, Donkeys, Mules and Horses in Tropical Agricultural Development. 3-6 September 1990. Centre for Tropical Veterinary Medicine, University of Edinburgh, Scotland, UK. 